\title{
Examination of the Depression Prevalence in a Turkish Sample
}

\section{Examen de la prevalencia de depresión en una muestra turca}

\author{
Mehmet Beyazsacli \\ University of Kyrenia, Northern Cyprus \\ ORCID: https://orcid.org/0000-0003-3163-6936 \\ Tugba Bankoglu* \\ University of Kyrenia, Northern Cyprus \\ ORCID: https://orcid.org/0000-0002-0606-9514
}

Received 01-14-20 Revised 03-03-20 Accepted 05-23-20 On line 06-12-20

\section{*Correspondence}

Email: Tugba.bankoglu@kyrenia.edu.tr
Cite as:

Beyazsacli, M., \& Bankoglu, T. (2020). Examination of the Depression Prevalence in a Turkish Sample. Propósitos y Representaciones, 8(3), e582. doi: http://dx.doi.org/10.20511/pyr2020.v8n2.582

(c) Universidad San Ignacio de Loyola, Vicerrectorado de Investigación, 2020. 


\section{Summary}

The aim of this study is to examine the effect size of depression in a Turkish sample with respect to gender and developmental periods. The studies of dissertation and articles completed during the period of 2004-2018 and covering Turkish sample have been examined through the method of Meta Analysis. The studies carried out, with the help of the depression measuring instruments, on a Turkish sample that has not taken any psychiatric diagnosis until that time, have been scanned through, by the use of the data bases such as; Google Academic, EBSCOhost and Web of Science. The criterion based sampling, which is one of the methods of sample selection, has been utilized. In the Meta Analysis; the effect value has been calculated through the use of the Cone Chart and Rank Relevancy Test of Begg and Mazumdar, Forest Chart analysis and Hedges's g. The random effects model has been utilized in the analysis. The general effect size of the depression with respect to gender has been found to be at low level and on women at relatively higher level. The effect size; for childhood and adolescence periods, which are considered to be the developmental periods, has been found out to be at low level, on young adults and adults at insignificant level, on elders at medium level and on women at relatively higher level. The results have been discussed, within the scope of literature, from the point of view of the effects onwoman depression and elderliness.

Keywords: Turkish, Effect Size, Depression

\section{Resumen}

El objetivo de este estudio es examinar el tamaño del efecto de la depresión en una muestra turca con respecto al género y los períodos de desarrollo. Los estudios de tesis y artículos completados durante el período 2004-2018 y que abarcan muestras turcas han sido examinados a través del método de Meta Análisis. Los estudios realizados, con la ayuda de los instrumentos de medición de la depresión, en una muestra turca que no ha recibido ningún diagnóstico psiquiátrico hasta ese momento, se han escaneado mediante el uso de bases de datos como; Google Academic, EBSCOhost y Web of Science. Se ha utilizado el muestreo basado en criterios, que es uno de los métodos de selección de muestras. En el metaanálisis; el valor del efecto se calculó mediante el uso de la Carta de Cono y la Prueba de Relevancia de Rango de Begg y Mazumdar, el análisis de la Carta Forestal y la g de Coberturas. El modelo de efectos aleatorios se ha utilizado en el análisis. Se ha encontrado que el tamaño del efecto general de la depresión con respecto al género está en un nivel bajo y en las mujeres en un nivel relativamente más alto. El tamaño del efecto; para los períodos de la infancia y la adolescencia, que se consideran períodos de desarrollo, se ha descubierto que es de bajo nivel, en adultos jóvenes y adultos en un nivel insignificante, en ancianos en un nivel medio y en mujeres en un nivel relativamente más alto. Los resultados se han discutido, dentro del alcance de la literatura, desde el punto de vista de los efectos sobre la depresión y la ancianidad de la mujer.

Palabras clave: Turcquía; Tamaño del efecto; Depresión.

\section{Introducción}

Depression disorder is seen among the mental health disorders, which affect the psychological well-being, in social and individual sense (Bodden et al., 2018). The American Psychiatric Association classifies the depression disorders as; failure to regulate destructive mood, major depression, dysthymia, substance or drug-related disorders, health-related disorders and undefined depression disorders. Depression restricts people in social life, isolates them and makes them feel helpless. Sleep problems, eating disorders, decreased attention/interest, concentration problems, relationship problems, affect the adjustment disorders and psychological well-being, 
negatively (DSM V, 2013). According to Ellis's Rational Emotional Behavioral Theory, depression is originated from an error of thought. Non-logical beliefs and dogmas increase the tendency to blame oneself and their environment by repeating themselves over time and thereby cause depression. Ellis explains this with the A-B-C theory. According to Aron T. Back's Cognitive Therapy theory, depression is predicated on how people perceive and evaluate experiences in the form of emotion and behavior (Corey, 2008: 300). According to Lewinson's Behavioral model, depression is a learned behavior and owing to behavioral changes the change of thinking hinders depression (Dogan, 2001).

Although theoretical approaches related to depression provide many perspectives, the literature studies report that $15 \%$ to $20 \%$ of adults face the risk of major depression at least once in their lifetime. Psychosocial stress factors such as death of a loved one, job loss, natural disasters, interpersonal problems and war are risk factors for depression (Oyama and Piotrowski, 2013). In the studies carried out on adolescents in American society, it is stated that there are high levels of family depression and related communication problems (Laura at al., 2018). In the studies conducted in OECD countries, it is reported that the prevalence of depression with respect to gender is higher in women (OECD, 2018). In Australian adolescents, the high depression symptoms are seen as a serious problem, which increases antisocial behaviors waiting for a solution, for the relationships in school environment (Di Manno at al., 2018). Studies indicate that problems connected with social environment and negative thought structures increase the level of depression and trigger substance abuse in youngsters (Bender at al., 2018; Nelson and Jason, 2018).

Studies in literature indicate that the prevalence in depression bears the features of a global problem that, day by day, negatively affects children, adolescents, adults and elderly individuals. In the studies conducted on the Pakistani university students, existence of prevalence of high depression thereon is reported (Noman at al. 2018). In a meta-analysis study conducted in Korean elderly, the prevalence of depression is emphasized (Whang et al., 2018). In the studies carried out on elderly in Finland, Poland, Spain and the United States, depression prevalence is emphasized (Domènech-Abella et al., 2018; Smith et al., 2018). Zhao et al. (2018). In the studies they conducted in the elderly nursing homes in China, they have drawn attention to the prevalence of depression. With the finding of another research conducted on Korean elderly people by Kang and Lee (2018), the high depression is referred.

In their study conducted on elderly people living in old age asylums in Taiwan, Hsiao and Chen (2018) emphasize the high level of depression. Buvneshkumar et al. (2018) make mention of the high prevalence of depression in the Indian elderly people. In the study conducted on adolescents, Stockdale et al. (2018) indicated the prevalence of depression. Shakeel et al. (2018), in their study on children of the European Minority families, they emphasized the prevalence of depression and its connection with the social support. In their study on Chinese migrant children, Tang et al. (2018) draw attention to high depression with the increase in social problems. Humphreys et al. (2018) report that the depressive disorder observed in the mothers of child care is transferred to the new generation depending upon the negative self-care relationship in children. In their research, Gallagher et al. (2018) report that depression is developed in children due to negative self-care behaviors.

The recent findings of the researches conducted in Turkey in the field of children's mental health, indicate that, the level of depressive disorders among children is at high level (Karaçetin et al., 2018). Sağar (2018), in his study on university students, indicates that mood disorders and moderate to high levels of depression exist, prevalently. Varma et al. (2012) reported that the level of depression in elderly people living in nursing homes is relatively higher than that of those living at home. Taycan et al. (2014), in the study examining the level of depression of the elderly people living in nursing home and at home together with their families, indicated relatively higher depression in the elderly people living at home, alone. In his study conducted by Özcan et al. (2013) on adolescents and young people the existence of depression, anxiety and low self-esteem 
is emphasized. These findings are supported by the similar depression findings conducted by Bucaktepe et al. (2015) on children. In their study on adolescents, Akça et al., (2018) reported that, one of the differences where the depression level of female students is higher than that of male students, is the increase of the male students' use of alcohol and drug abuse due to the upsurge in the level of depression.

In their study conducted on high school adolescents, it is reported by Öztop et al., (2011) that the increase in the level of depression was effective in the frequency of aggression and committing crime. Sahin and Tekin (2014) reported that there are serious problems in domestic relations and communication quality depending upon the increase in the level of depression. Similar findings of the studies conducted on children are also in the direction of the fact that negativities are experienced on domestic relations and academic success together with the increase in depression level (Adana et al., 2015). Children, adolescents, adults and elderly individuals take place, together, in the social structure. When one examines the literature studies related to elderly depression in the Turkish Society, attention is hereby drawn to the high level of depression and anxiety of the elderly people living alone at home (Ağırman et al., 2015: Ay et al., 2017: Bingöl et al., 2017) and elderly women (Elkin, 2016).

Domestic and foreign study findings indicate that the prevalence of depression is an important mental health problem. Therefore, this study is needed to understand the prevalence and effect size of depression on a Turkish sample. The problem statement of the study was expressed as "What is the prevalence of depression in Turkish sample?" In line with this general purpose, what is the effect size and direction of depression with respect to gender? Answers will be sought to the said questions. With this study, it is expected to contribute to the experts working in the field of determining the depression risk areas and creating intervention plans. This study is considered to be important as it is the first study to analyze the prevalence of depression on a Turkish sample, in terms of gender, developmental periods and life space.

\section{Method}

The effect size of the depression, with respect to gender and developmental periods, conducted on a sample in Turkey, has been examined by utilizing the method of Meta Analysis. The Meta analysis is a form of analysis, which procures reaching a general conclusion by combining the results obtained through different studies (Dincer, 2014:2).

\section{Data Collection}

Data were obtained from the thesis and article studies conducted between the years 2004-2018. Quantitative studies, in which depression measurement tools were applied in the databases of; ULAKBIM, YÖK, Google Academic, EBSCOhost and Web of Science were scanned through. The study population covers the Turkish sample. The method of Criterion sampling, which is one of the Methods of Sampling Selection, was used. As criteria in the study, the conditions sought are as follows; 1 . The state of giving place to the studies conducted on a Turkish sampling, 2. Its including the quantitative studies of the type of screening. 3. Its containing the studies on children, adolescents, young adults, adults and elderly individuals, 4. Its being of the type of study that takes in its scope the arithmetic mean, standard deviation and sampling sizes, in accordance with the results of the analysis of data, 5. Its containing the permitted theses and articles published in the literature, 6 . Its containing the reliability coefficient in the studies. The 26 studies, which are deemed suitable for these criteria are included in the Meta Analysis. The study includes 3490 women and 3576 men.

\section{Data Analysis}

A master key has been created before the Meta Analysis, from the point of view of the provision of criteria equals. In the master key; author of the research, year of the study, subject of the study, 
validity and reliability coefficients of the utilized measuring instruments, arithmetic mean, standard deviation and sample size, have all been encoded. In the analysis, the software of the Comprehensive Meta Analysis has been used. In Meta analysis, primarily, the value of biasness has been examined in accordance with the conical chart and the rank correlation test of Begg and Mazumdar $(\mathrm{p}<0.05)$. Following, the effect sizes have been calculated as per the variables of child, adolescent, young adult and adult, who are considered to be among the gender and developmental periods, and in accordance withthe Forest Chart and Hedges's g value. The values of analyses have been carried out on the scores of the experimental and control groups. The sample made up of women has been included in the experimental group and the sample made up of men has been given place in the control group. The effect size values classified according to the levels have been as follows: Insignificant $(\mathrm{g}<0.15)$, low $(0.14<\mathrm{g}<0.40)$, medium $(0.39<\mathrm{g}<0.75)$, high $(0.74<\mathrm{g}<1.10)$, very high $(1.9<\mathrm{g}<1.45)$ and proper $(\mathrm{g}>1.44)$ (Dincer, 2014:13).

\section{Reliability of the study}

In calculating the effect size of the Meta analysis, the value of $\mathrm{Q}$ has been used and, depending upon the heterogeneous distribution, the random effects model has been utilized. Level of significance of the study is 0.05 . Regarding the reliability value, there will be a need for an additional amount of 559 studies, which will make the study insignificant ( $p>0.05)$ at the end of the Classical Fail-Safe N Test. This value indicates that the study isreliable.

\section{Results}

In the analysis, primarily, the publication bias pertaining to individual studies has been tested. The Conical Chart of biasness is presented as in Figure 1.

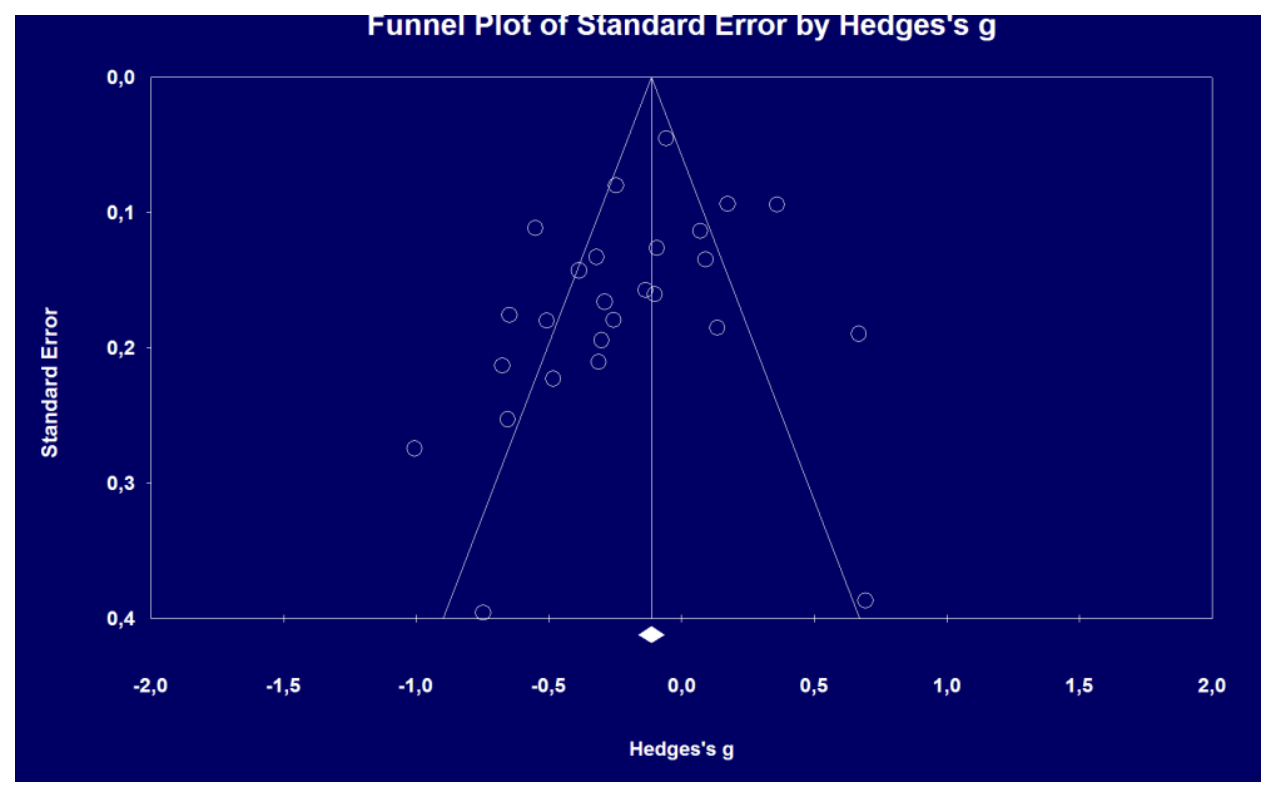

Figure 1. Conical Chart

The individual studies in Figure 1 shows distribution of the conical graph in and around of the middle line. This situation indicates biasness. For the analysis of absolute biasness, the Begg and Mazumdar's rank relationship test is used. According to this test, the Tau coefficient is close to 1.00 and the $p$ value is greater than 0.05 (Tau $=-0.243, p=0.082)$. This result absolutely shows that the study does not contain publication bias. For the purpose of study, the overall effect size of depression in the sample was tested with homogeneity-heterogeneity graph and presented in Figure 2. 


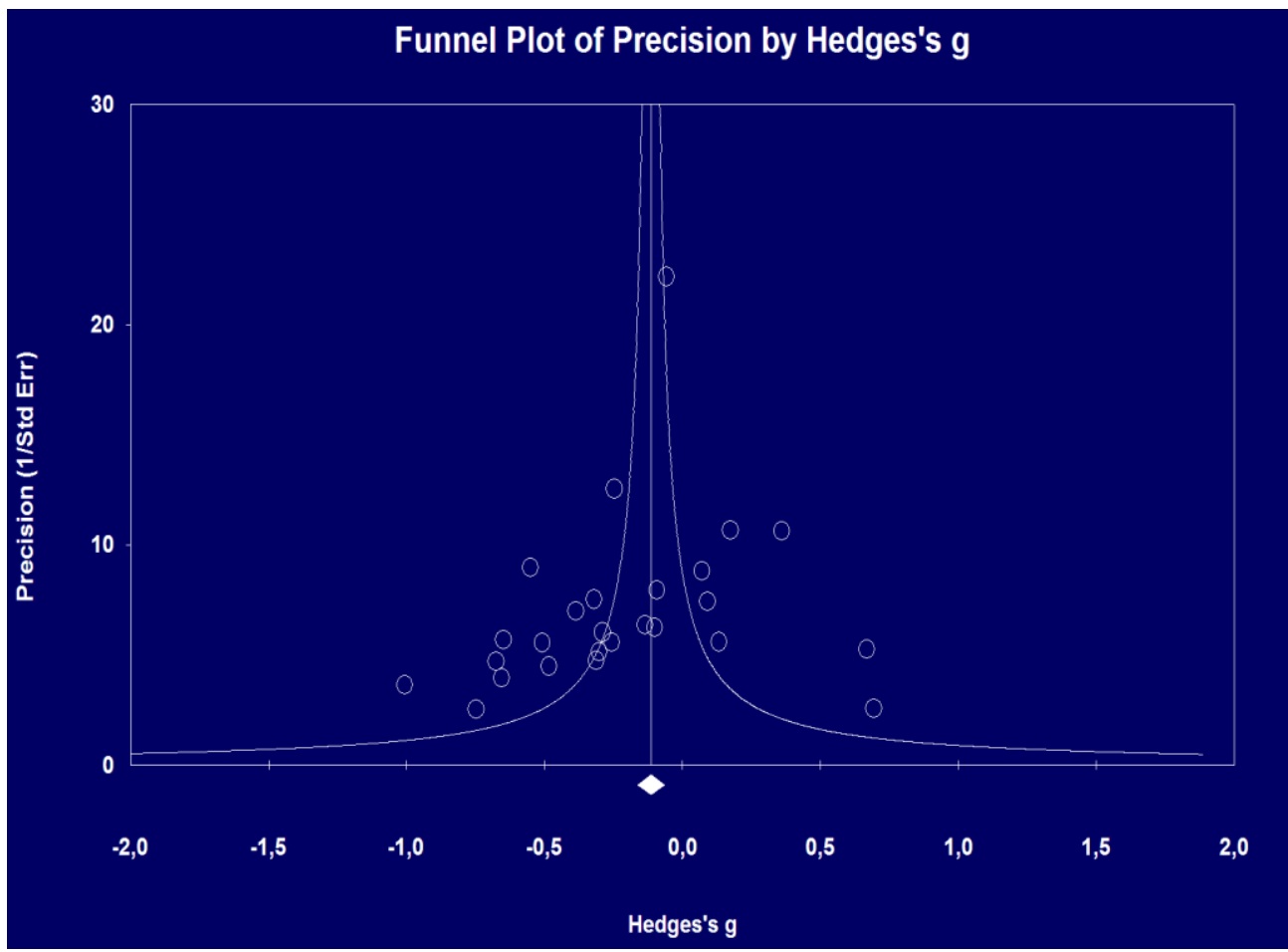

Figure 2. Homogeneity and Heterogeneity Graph

In the graph of Figure 2, it is indicated that the homogeneity of the existence of all the studies to be inside the conical chart, and the heterogeneity of the nonexistence of them not to be inside of it. However, due to the reason that most of the studies are outside of the conics, the values of Q statistics have been looked through. Results have been presented in Table 1.

Table 1.

Analysis Results of the Constant and Random Effects

\begin{tabular}{lrrlllll}
\hline Model & $\mathrm{N}$ & $\mathrm{Z}$ & $\mathrm{p}$ & $\mathrm{Q}$ & $\mathrm{df}$ & ${ }^{*} \mathrm{p}$ & $\mathrm{I}^{2}$ \\
\hline Fixed & 26 & -4.632 & 0.000 & \multirow{2}{*}{133.826} & \multirow{2}{*}{25} & \multirow{2}{*}{0.000} & 81.319 \\
Random & 26 & -3.055 & 0.002 & &
\end{tabular}

In Table 1, it has been found out that the studies have shown a heterogeneous distribution with respect to gender $(\mathrm{Q}=133.826, \mathrm{df}=25, * \mathrm{p}<0.01)$. Accordingly, in the calculation of the general effect size, the random effects model has been used. The Forest Chart showing the effect size value has been presented in Figure 3. 


\begin{tabular}{|c|c|c|c|c|c|c|c|}
\hline \multirow[t]{2}{*}{ Study name } & \multicolumn{7}{|c|}{ Statistics for each study } \\
\hline & $\begin{array}{c}\text { Hedges's } \\
g\end{array}$ & $\begin{array}{l}\text { Standard } \\
\text { error }\end{array}$ & Variance & $\begin{array}{l}\text { Lower } \\
\text { limit }\end{array}$ & $\begin{array}{l}\text { Upper } \\
\text { limit }\end{array}$ & z-value & $\mathrm{p}$-Value \\
\hline Arslan $2011 \mathrm{~g}$ & $-0,320$ & 0.133 & 0.018 & -0.580 & -0.080 & $-2,415$ & 0.018 \\
\hline Arss $\operatorname{lnn} 2011 \mathrm{~b}$ & $-0,092$ & 0.128 & 0.018 & $-0,339$ & 0.155 & $-0,732$ & 0.484 \\
\hline Sancakoölu 2012 & $-0,301$ & 0.194 & 0,038 & -0.881 & 0,080 & $-1,547$ & 0,122 \\
\hline Emiroôlu 2011 & -0.289 & 0.188 & 0,028 & -0.815 & 0.038 & $-1,745$ & 0.081 \\
\hline Ören 2007 & 0.091 & 0.135 & 0.018 & -0.173 & 0,355 & 0.878 & 0.499 \\
\hline Karakgya 2004 & $-0,550$ & 0.111 & 0.012 & $-0,789$ & $-0,332$ & $-4,937$ & 0.000 \\
\hline Türklep 2007 & $-0,247$ & 0.080 & 0,006 & -0.403 & -0.091 & $-3,097$ & 0.002 \\
\hline Dyinn 2018 & 0.174 & 0.094 & 0.009 & $-0,009$ & 0,368 & 1.880 & 0.083 \\
\hline Deveci 2013 & $-0,136$ & 0.157 & 0.025 & -0.444 & 0,172 & -0.885 & 0,387 \\
\hline Ceyhan 2011 & 0,380 & & 0,009 & 0,175 & 0.545 & 3.824 & 0.000 \\
\hline Çelikel 2008 & $-0,058$ & 0.045 & 0.002 & $-0,148$ & 0.031 & $-1,278$ & 0.201 \\
\hline Koksal & $-0,101$ & 0,180 & 0.026 & $-0,415$ & 0.213 & -0.828 & 0.530 \\
\hline Eozkurt 2004 & 0.070 & 0,114 & 0.013 & $-0,152$ & 0.293 & 0.819 & 0.536 \\
\hline Sütoluk 2004 & -0.483 & 0.223 & 0.050 & -0.919 & $-0,047$ & $-2,169$ & 0,030 \\
\hline Dimpek 2010 & $-0,648$ & 0.178 & 0,031 & -0.993 & $-0,304$ & $-3,690$ & 0.000 \\
\hline Top 2010 & $-0,655$ & 0.253 & 0.084 & $-1,151$ & $-0,180$ & $-2,593$ & 0.010 \\
\hline Unnal 2005 & $-0,312$ & 0.210 & 0,044 & -0.725 & 0.100 & $-1,488$ & 0.137 \\
\hline Bingöl 2010 & $-0,386$ & 0.143 & 0,020 & -0.866 & $-0,108$ & $-2,702$ & 0.007 \\
\hline HsojhassnoËlu 2009 & $-1,005$ & 0.274 & 0.075 & $-1,543$ & -0.468 & -3.688 & 0.000 \\
\hline Ozen 2008 & $-0,508$ & 0.180 & 0.032 & -0.881 & $-0,155$ & $-2,823$ & 0.005 \\
\hline Zincir 2008 & $-0,875$ & 0.213 & 0,045 & $-1,093$ & -0.258 & $-3,171$ & 0.002 \\
\hline |zgar 2009 & $-0,258$ & 0.179 & 0,032 & -0.007 & 0,095 & $-1,427$ & 0.154 \\
\hline Aydýn $2009 \mathrm{a}$ & -0.747 & 0,396 & 0.157 & $-1,523$ & 0,028 & $-1,889$ & 0.059 \\
\hline Aydýn $2009 b$ & 0,693 & 0,387 & 0.150 & $-0,065$ & 1.452 & 1,792 & 0,073 \\
\hline Erol 2007 & 0,688 & 0,190 & 0.036 & 0.297 & 1.040 & 3.524 & 0,000 \\
\hline \multirow[t]{2}{*}{ Canbal 2012} & 0,133 & 0.179 & 0.032 & -0.217 & 0.483 & 0.745 & 0.456 \\
\hline & $-0,194$ & 0,063 & 0,004 & $-0,318$ & $-0,069$ & $-3,055$ & 0,002 \\
\hline
\end{tabular}

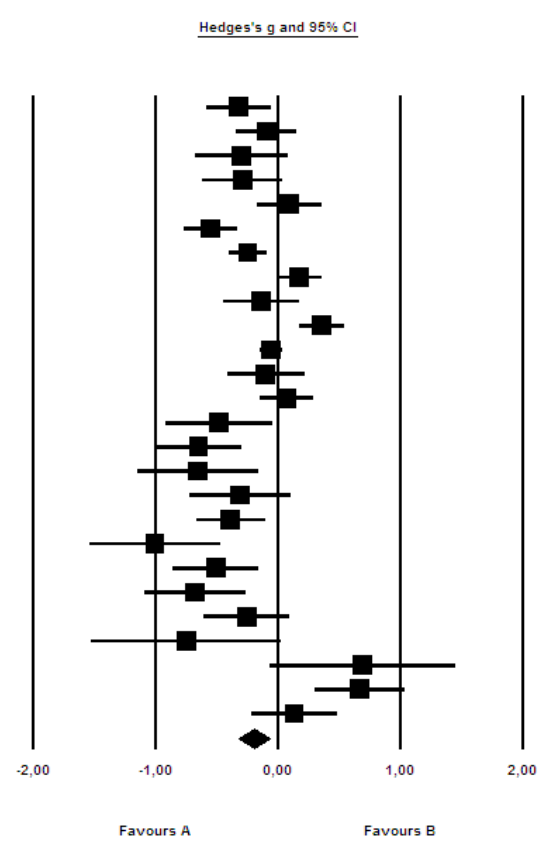

$\begin{gathered}\text { Relative } \\ \text { weight }\end{gathered}$ weight
weive

4,37

4,45
3,58

3,94

4,34
4,83

\section{Meta Analysis}

Figure 3. Forest Chart

In Figure 3, study weights are distributed within the range of (-2.00-2.00). The generaleffect size is presented in Table 2.

Table 2.

General Effect Size of Depression With Respect to Gender

\begin{tabular}{|c|c|c|c|c|c|c|c|c|c|c|c|c|}
\hline \multirow{2}{*}{ Variable } & & \multirow[b]{2}{*}{ g } & \multirow{2}{*}{$S_{\text {error }}$} & & \multirow{2}{*}{ z } & \multirow{2}{*}{ Q } & \multirow{2}{*}{$\mathrm{I}^{2}$} & \multicolumn{3}{|c|}{ Lower } & \multirow[t]{2}{*}{ Upper } & \multirow{2}{*}{ "p } \\
\hline & & & & & & & & Limit & & Limit & & \\
\hline & & - & & & - & & & & & & - & \\
\hline Depression & 0.194 & & 0.063 & 3.055 & & 133.710 & 81.303 & & -0.318 & 0.069 & & 0.002 \\
\hline
\end{tabular}

The overall effect size of depression, with respect to the gender variable, was observed to be at a lower ebb $(g=0.194)$ and a higher level from the point of view of women. In other words, it can be said that being a woman increases the effect of depression. Again, in accordance with the study purposes, special effect sizes according to developmental periods have been examined and the results of the analysis are presented in Table 3. 
Table 3.

The Effect Size of Depression With Respect to the Developmental Periods

\begin{tabular}{lllllllll} 
Period & $\mathrm{N}$ & $\mathrm{g}$ & Standart Error & Lower Limit & Upper Limit & $\mathrm{z}$ & $\mathrm{p}$ & Impact Range \\
\hline $\begin{array}{c}\text { Children } \\
\text { Adolescence }\end{array}$ & 3 & -0.219 & 0.083 & -0.381 & -0.057 & -2.644 & $0.008^{* *}$ & Low \\
$\begin{array}{c}\text { Young } \\
\text { adults }\end{array}$ & 4 & -0.254 & 0.126 & -0.501 & 0.008 & -2.025 & $0.043^{*}$ & Low \\
\hline Adults & 6 & 0.066 & 0.081 & -0.093 & 0.225 & 0.813 & $0.415^{* * *}$ & Insignificant \\
Elderly & 4 & 0.106 & 0.333 & -0.547 & 0.759 & 0.318 & $0.751^{* * *}$ & Insignificant \\
& 9 & -0.478 & 0.100 & -0.673 & -0.282 & -4.794 & $0.000^{* *}$ & Medium \\
\end{tabular}

In Table 3, the depression effect size was observed in children $(g=-0.219)$ and in adolescents $(\mathrm{g}=-0.254)$ to be at low level and in the favor of males. In young adults $(\mathrm{g}=0.066)$ and adults $(\mathrm{g}=0.106)$ it was observed to be at insignificant level. It was found to be at moderate level on elderly people $(g=-0.478)$ and more effective on women.

In accordance with the study purposes, the distribution of depression effect size according to the living area is presented in Table 4 . In order to increase the statistical accuracy of the results, the data that are two or more were included in the analysis.

Table 4.

The Depression Effect Size According to Living Space

\begin{tabular}{|c|c|c|c|c|c|c|c|c|c|}
\hline $\begin{array}{l}\text { Living } \\
\text { Space }\end{array}$ & $\mathrm{N}$ & $g$ & Standart Error & $\begin{array}{l}\text { Lower } \\
\text { Limit }\end{array}$ & $\begin{array}{l}\text { Upper } \\
\text { Limit } \\
\end{array}$ & $\mathrm{z}$ & $\mathrm{p}$ & Range & Impact \\
\hline $\begin{array}{l}\text { Nursing } \\
\text { home }\end{array}$ & 4 & -0.678 & 0.119 & -0.910 & -0.446 & -5.720 & $0.000 * *$ & & Medium \\
\hline $\begin{array}{l}\text { Own } \\
\text { home }\end{array}$ & 6 & -0.268 & 0.133 & -0.529 & -0.008 & -2.017 & $0.044^{*}$ & & Medium \\
\hline School & 3 & -0.096 & 0.068 & -0.228 & 0.037 & -1.417 & $0.156 * * *$ & & Insignificant \\
\hline
\end{tabular}

According to the data in Table 4, the effect size on the elderly women who pass their times at nursing homes, has been at medium level $(g=-0.678)$. The effect size on the elderly women who pass their times at their own homes has been found to be at low level $(g=-0.268)$. The effect size on the student-group, who pass their daily living mostly at school, however, has been found to be at insignificant level $(\mathrm{g}=-0.096)$.

\section{Discussion and Conclusion}

In this study, when the overall effect size of depression was examined according to the gender variable only, the overall effect size was found to be moderate in the elderly people and relatively lower levels in children. In addition, the findings show that men are exposed to a relatively lower depression effect compared to women. It can be said that the elderly women take place as a risk factor in the overall effect size. The findings in this study are in line with the results of the domestic and foreign studies (Çifçili et al., 2006; Izgar, 2009; Kim, 2009; Arguvanlı et al., 2015; Lansari et al., 2015; Salk et al., 2016; Bishwajit et al., 2017).

In the study, according to the life space variable, the depression effect size of the elderly in the nursing home was found to be moderate and in favor of males. Many findings of the studies conducted on the elderly people, in general, have the quality of supporting the increase in depression (Altıntaş et al., 2006; Tözün and Ünsal, 2008; Altay and Avc1, 2009; Bingöl et al., 
2010; Top et al., 2010; Canbal et al. Varma et al., 2012; Unsar et al., 2015; Wang et al., 2018; Domènech-Abella et al., 2018; Smith et al., 2018; Zhao et al., 2018; Kang and Lee, 2018; Hsiao and Chen, 2018; Buvneshkumar et al., 2018). Akça and Figen (2008) stated that, for lederly people, living at home with low life satisfaction causes high depression (Sahin and Yalçın 2003; Aksülü and Doğan, 2004). In some literature studies, it has been reported that there is no significant difference, from the point of view of the level of depression, between elderly people living in nursing homes and the elderly people living at homes (Gülseren et al., 2000; Akça et al., 2014). In this study, the higher depression in elderly people, may be due to lack of social support (Yazgan et al., 2006; Altay and Avc1, 2009; Varma, 2012).

The prevalence of depression was found to be of insignificant level for children, adolescents, young adults and adults. In their study related to the effect of depression on gender in young adults, Di1n (2016) and Finan et al. (2018) reported an insignificant effect size. Deveci et al., (2013), in their study conducted on the health college students, found the level of depression in young adults as high. This result, which differs from the findings of the study, may be due to the human health responsibility imposed on the students. A finding of another study conducted on American adults also emphasizes the similar increase in the level of depression (Koh, 2018). This difference may be due to insomnia, obesity, social isolation, increase in the level of alcohol and substance abuse, which were reported through the literature (Ceyhan and Ceyhan, 2011; Andersson et al., 2013; Yuko et al., 2015; Trudeau, 2016; Irina et al. Jenkins et al., 2016; Adelyn et al., 2016; Holshausen, 2016; Jenkins, 2016; Polshkova, 2016; Bender et al., 2018; Nelson and Jason, 2018; Noman at al. 2018). Also, in some studies conducted on adolescent depression, high depression has been reported (Halil et al., 2013: Bellamy and Hardy, 2015; Krysia, 2015; Wolanin, 2016; Stockdale et al. 2018). This finding may arise from the cultural differences specific to foreign samples or severity of the risk factors triggering depression.

In this study, it has been found that the level of depression is higher in girls than in boys. This finding shows parallelism with the other study findings (Arslan et al., 2011; Emiroglu and Murat, 2011; Sancakoglu and Sayar, 2012; Swenda and Henry, 2016; Proskurina et al., 2016; Barnes et al., 2017; Shakeel et al., 2018; Tang et al., 2018; Humphreys et al., 2018; Gallagher et al., 2018; Karaçetin et al., 2018). When the results of this study are associated with the literature, it can be said that the frequency of exposure to adverse events supports the severity and direction of depression.

Important findings have been found in this study, in which the prevalence of depression was examined by gender in a Turkish sample. First of all, it has been observed that the general depression aspect according to gender varies according to developmental periods. It has been observed that the direction of depression on children, adolescents and the elderly people is in the favor of males whereas on adolescents, young adults and adults it is in the favor of females. The state of its being in the favor of males for children and adolescents may be due to the cultural impact of the patriarchal family structure in the Turkish society. The relatively higher depression perceived by women for elderly people, children and adolescents may be the result of inadequate social support. According to the developmental stages, the effect size of depression in the elderly was observed to be relatively higher compared to other developmental periods.

This result is supported by the literature studies as well. According to the life space variables, the depression level in elderly women living in nursing homes was observed to be at higher level compared to males. According to the literature findings, these results may be due to lack of social support. This study, with its findings as well, supports the probability propounded that a lower level of depression effect in school and home environment is encountered. Regarding the important result of this study supported by the literature, it can be said that the general way of change of depression prevalence and the effect size depending on the risk severity, can be supported in generalization. As in every study, there are some limitations in this study as well. This study has been carried out by using the arithmetic mean, standard deviation, sample size and sex data, as base. Therefore, the results are limited to gender variable data. In further studies, it is 
suggested to carry out studies to determine the prevalence of depression effect size in terms of different variables. According to the results of the study, it is recommended to support the problems of elderly people with higher risk of depression through descriptive studies. It is also recommended to intensify the studies on the causes of depression risk for girls in children and adolescents. Focus studies are recommended to reduce the risk of depression observed in women living in elderly nursing homes. It is proposed to inform the nurses and nursemaids in nursing homes, teachers at schools and family members at homes in the fight against depression.

\section{References}

Adelyn, A., Maria, M., Eric, F. \& Pamela, S. (2016). Parental social networks during childhood and off spring depression in early adulthood: a lifecourse approach. Depression \& Anxiety, 33(11): 1031-1038.

Adana, F., Uluman, Ö., Arslantaş, H. \& Ergin, F. (2015). Depressive symptom incidence and related factors in primary education students. Journal of Psychiatric Nursing, 6(1):18.

Ağırman, E., Gençer, M.Z., Arıca, S., Kaya, E. \& Eğici, M.T.(2017). Depression and loneliness levels among the older people, a comparison between living alone, living with family or living at nursing home. J. Contemp Med.,7(3): 234-240.

Altıntaş, H., Attila, S., Sevencan, F., Akçalar, S., Sevim, S., Solak, Ö. S., Sahin, E. K. \& Velagiç, Z. (2006). The screening of depression symptoms of the elderly living in a residential home in Ankara. TAF Preventive Medicine Bulletin,5(5): 332-342.

Altay, B. \& Avc1, I. A. (2009). Some features of the elderly living in Samsun nursing home. Turkish Journal of Geriatrics, 12(3): 147-155.

Andersson, L. M. C., Schierenbeck, I., Strumpher, J., Krantz, G. Topper, K., Backman, G., Ricks, E. \& Van R. D. 82013). Help-seeking behaviour, barriers to care and experiences of care among persons with depression in Eastern Cape, South Africa. Journal of Affective Disorders. 151(2), 439-448.

Akça, F. \& Sahin, G. (2008). A study comparing the quality of life and related psychological symptoms of the elderly living in nursing homes, with the ones living with their families. Turkish Journal of Geriatrics, 11(4):190-199.

Akça, A. S. D.,Saraçlı Ö., Emre, U.,Atasoy, N., Güdül, S., Barut, B. Ö., Şenormancı, Ö.,

Büyükuysal, Ç., Atik, L. \& Atasoy, H. T. (2014). Relationship of cognitive functions with daily living activities, depression, anxiety and clinical variables in hospitalized elderly patients. Archives of Neuropsychiatry, 51: 267-274.

Akça, S.Ö., Filiz Selen, F., Demir, E. \& Demir, T. (2018). Effect of Gender and Age Differences on Depression of Adolescents, Anxiety Disorder, Self-Injury, Psychosis, Post-Traumatic Stress Disorder, Alcohol-Drug Addiction and Attention Deficit Hyperactivity Disorder. Dicle Med J., 45(3): 255-264.

Aksülü, N. \& Doğan, S. (2004). Relationship of social support and depression in institutionalized and non-institutionalized elderly. Anatolian Journal of Psychiatry, 5: 76-84.

Arslan, C., Güllü, M. \& Tutal, V. (2011). Analysing the depression states of elementary school students who do sports or not according to some variables. Nigde University Journal of Physical Education And Sport Sciences, 5(2):120-132.

Arguvanlı, S., Akın, S., Şafak, E. D., Mucuk, S., Öztürk, A., Mazıcıoğlu, Kızılçay, H. D., \& Göçer, Ş. (2015). Prevalance of cognitive impairment and related risck factors in community-dwelling elderly in Kayseri, Turkey. Turkish Journal of Medical Sciences, 69(10): 1087-1090.

Ay, S.,Ünübol, H.,Ezer, S.,Omay, O. \& Sayar, G.H. (2017). Evaluation of the Relationship Between Caregiver Burden, Coping Styles and Levels of Anxiety and Depression in Caregivers of Old Age Patients. Fam. Pract. Palliat Care,2(3):38-44.

Barnes, S., Howell, K., Thurston, I. \& Cohen, R. (2017). Children's attitudes toward aggression: Associations with depression, aggression and preceived maternal/peer responses to anger. Journal of Child \& Family Studies. 26(3), 748-758.

Bellamy, S. \& Hardy, C. (2015). Factors predicting depression across multiple domains in a 
national longitudinal sample of canadian youth. Journal of Abnormal Child Psychology. 43(4): 633-643.

Begun S., Bender, K. A., Brown, S. M., Barman-Adhikari, A. \& Ferguson, K. (2018). Social connectedness, self-efficacy, and mental health outcomes among homeless youth. Youth \& Society. 50(7):989-1014.

Bingöl, G., Demir, A., Karabek, R., Kepenek, B., Yıldırım, N. \& Kaytaz, E. G. (2010). Analysing the depression levels of the individuals more than 65 in terms of some variables. Göztepe Medical Journal, 25(4):169-176.

Bingöl, C., Sözeri Varma, G., Enli, Y. \& Karaca, Ö.(2017). A phenomenological comparison of elderly depression and adult depression. Anatolian Journal of Psychiatry, 5(18):446452.

Bishwajit, G., O'Leary, D. P., Ghosh, S., Sanny, Y., Shangfeng, T. \& Zhanchun, F. (2017). Association between depression and fruit and vegatable consumption among adults in South Asia. BMC Psychiatry, 17(15): 2-9.

Bodden, D.H.M., Stikkelbroek, Y. \& Dirksen, C.D. (2018). Societal burden of adolescent depression, an overview and cost-of-illness study. Journal of Affective Disorders, 7(241): 256-262.

Bucaktepe, P.G.E., Çelik, S.B.,Tekeli, A.,Öztekin, C., Çelepkolu, T., Demir, V. \& Değirmen, E. (2015). Frequency of depressive symptoms in health workers' children. Dicle Med $J ., 42(2): 214-221$.

Canbal, M.,Şencan, İ., Sahin, A., Kunt, Ş., Çavuş, U. Y. \& Tekin, O. (2012). Eff ects of depression and life factors on social network score in elderly people in Çankaya, Ankara. Turkish Journal Medicine Science, 42(4): 725-731

Ceyhan, E. \& Ceyhan, A. A. (2011). Loneliness and depression levels of students using a universitycounseling center. Education and Science, 36(160): 81-92.

Çifçili, S., Yazgan, Ç. \& Ünalan, P. (2006). Results of depression screening among elderly residents Turkish Journal of Geriatrics, 9(3): 122-125.

Di1n, A. A. \& Harris, C. L. C. (2016). Understanding gender and urban/rural differences in depressive symptoms: Insights from university students in Turkey. Electronic Journal of Social Sciences, 15(56): 21-33.

Di Manno, L., Macdonald J.A.,Youssef G.J., Little K. \& Olsson C.A. (2018). Psychosocial profiles of adolescents from dissolved families: Differences in depressive symptoms in emerging adulthood. Journal of Affective Disorders, 13(241):325-337.

Öztop, D.B., Öztürk, A., Ünalan, D., Mazıcıŏlu,M. Balc1, E. \& Gün, İ. (2011). The prevalence of depression and behavioral problems in the high school students. Anatolian Journal of Psychiatry, 12:204-211.

Corey, G.(2008). Theory and Practice of Counseling and Psychoterapy. Çev: Turgay Ergene. Ankara. Mentis Publishing.

Domènech-Abella, J.Mundó, J.,Leonardi, M.,Chatterji, S.,Tobiasz-Adamczyk, B.,Koskinen, S.,Ayuso, Mateos, J.L. \& Haro, J.M. (2018). The association between socioeconomic status and depression among older adults in Finland, Poland and Spain: A comparative cross-sectional study of distinct measures and pathways. Journal of Affective Disorders. 241(8):311-318.

Elkin, N. (2016). Assessment of the depression frequency and life satisfaction in the elderly people applying to family health center. Mersin University, Health Science Magazine, 9(1): 9-21.

Emiroglu, M. \& Murat, M.(2011). Determination of socio-demographic variables predicting depression levels of high school students. Electronic Journal of Social Sciences, 10(38): 262-274.

Finan L.J., Ohannessian C. \& Gordon M. S. (2018). Trajectories of depressive symptoms from adolescence to emerging adulthood: the influence of parents, peers, and siblings. Developmental Psychology, 54(8):1555-1567.

Gallagher, S., Pilch,M. \& Hannigan, A. (2018). Prior depressive symptoms and persistent child problem behaviours predict future depression in parents of children with developmental disabilities: The growing up in Ireland cohort study. Research In Developmental Disabilities, 80:170-179. 
Gülseren, Ş., Koçyiğit, H., Erol, A., Bay, H.,Kültür, S., Memiş, A. \& Vural, N. (2000). Cognitive functions, mental disorders, level of depressive symptoms and quality of life in elderly residents of a nursing home. Turkish Journal of Geriatrics, 3(4): 133140.

Gül, A., Gül, H., Özen, N. E. \& Battal, S. (2016). The relationship between anxiety, depression and dissociative symtoms on the basis of childhood traumas. Journal of Mood Disorders, 6(3): 107-15.

Halil, Ö., Burak S., Beyhan, B., Mustafa, Ç. Şeref, C.G. \& Mesut, Y. (2013). The relationship of the adolescence and young adulthood. Journal of Mood Disorders,3(3):107-137.

Holshausen, K., Bowie, C. \& Harkness, K. (2016). The relation of childhood maltreatment to psychotic symptoms in adolescents and young adult with depression. Journal of Clinical Child \& Adolescent Psychology. 45(3): 241-247.

Humphreys, K. King, L., Choi, P. \& Gotlib, I. H. (2018). Maternal depressive symptoms, selffocus, and caregiving behavior. Journal of Affective Disorders. 238(7):465-471.

Hsiao, Y.C. \& Chen, C.Y. (2018). Exploring Individual, Family, and Extrafamilial Factors Associated With Depression Among Elderly Residents of Care Settings. International Journal Of Aging \& Human Development, 86 (3): 219-241.

Izgar, H. (2009). An investigation of depression and loneliness among school principals. Educational Sciences: Theory \& Practice, 9 (1): 231-258.

Irina, L., Camacho, I., Esther, I. C. M., Consuelo, V. M. \& Marco, Z. Z. (2016). Record Title: Relationship among obesity, depression, and emotional eating in young adults. Appetite, 107: 639-644.

Jenkins, W. D. \& Botchway, A. Young adult with depression are at increased risk of sexually transmitted disease. Preventive Medicine. 88: 86-89.

Karaçetin, G., Arman, A.R. \& Fis N.P. (2018). Prevalence of childhood affective disorders in Turkey: An epidemiological study. Date of Electronic Publication,30(238):513-521.

Kang, Y. \& Lee, E. (2018). Quality of Life and Its Factors in Korean Elderly With Mild Cognitive Impairment. Clinical Nursing Research. 7( 27):871-889.

Kim, O. (2009). Cognitive impairment and depression in community-dwelling older Korean women. Psychological Reports, 105(2): 569-74.

Krysia, N. M. (2015). Disadvantaged family back ground and depression among young adults in the United states: The roles of chornic stres and self-esteem. Stress \& Health: Journal of the International Society for the Investigation of Stress. 31(1): 52-62.

Koh, E. (2018). Prevalence and predictors of depression and anxiety among Korean Americans. Social Work in Public Health, 33(1):55-69.

Lansari, R., Nefzi, H., Smaoui, S., Azzouz, M. A., Jeridette, S., Derouich, S., Meziou, O., Mnif, L. \& Melki, W. (2015). Depression of the Institutionalized Elderly. European Psychiatry, 1(30):1466-1469.

Noman, R., Qurat U.A.K. \& Syeda, S. F. (2018). Stress, Anxiety and Depression in students of aprivate medical school in Karachi Pakistan. Pak. J. Med. Sci, 3(34):1-7.

Nelson, J.M. \& Liebel S.W. (2018). Anxiety and depression among college students with attention-deficit/hyperactivity disorder (ADHD): Cross-informant, sex, and subtype differences. Journal of American College Health,66(2):123-132.

Oyama, O. \& Piotrowski, N.A. (2013). Depression. Magill's Medical Guide, 6-12.

OECD (2018). How is depression related to education? Education indicators in focus. $O E C D$ Publishing, 182.

Unsar, S., Dindar, I. \& Kurt, S.,(2015). Activities of daily living, quality of life, social support and depression levels of elderly individuals in Turkish society. The Journal of The Pakistan Medical Association 65(6);642-6.

Polshkova, S., Chaban, O. \& Walton, M. A.(2016). Alcohol use depression and hight-risk occupations among young adult in the Ukraine detail only available. Substance Use \& Misuse. 51(7): 948-951.

Proskurina, T., Mykhailova, E., Matkovska, T., Reshetovska, N. \& Matkovska, A. (2016). Clinical and psychopathological factors fort he development of recurrent depression in children at puberty. European Psychiatry. 33: 145-146. 
Salk, R. H., Petersen, J. L., Abramson, L.Y. \& Hyde, J. S. (2016). The contemporary face of gender differancs and smilarities in depression throughout adolescence: Development and chronicity. Jounal of affective disorders, 205: 28-35.

Sancakoglu, S. \& Sayar, M. K. (2012). Relation between socioeconomic status and depression, anxiety, and self-esteem in early adolescents. New Symposium Journal, 50(4): 207220.

Sahin, E. M. \& Yalçın, B. M. (2003). Comparing the incidences of depression at the elderly living in nursing home or at their own homes. Turkish Journal of Geriatrics, 6(1): 1013.

Sahin, V. \& Tekin, O. (2014). Relationship Between Family Functions, Depression and Anxiety Scores. Clinical Psychiatry, 17(4):109-118.

Sağar, M.E. (2018). Examination of depression levels of some faculty of education according to some variables. Gümüshane University Institute of Social Sciences, 9(23): 23-42.

Serap, E.T., Fatma D.K. \& Okan T. (2014). The effect of the nursing home or residence on the level of depression and anxiety in the elderly. Clinical Psychiatry,,17:73-82.

Shakeel, N.,Sletner, L.,Falk, R.,Slinning, K.,Martinsen, E., Jenum, A.,Eberhard-Gran, M. \& Falk, R.S. (2018). Prevalence of postpartum depressive symptoms in a multiethnic population and the role of ethnicity and integration. Journal of Affective Disorders, 241(10):49-58.

Smith, L.,White, S. Stubbs, B., Hu, L.,Veronese, N.,Vancampfort, D.,Hamer, M.,Gardner, B. \& Yang, L. (2018). Depressive symptoms, handgrip strength, and weight status in US older adults. Journal of Affective Disorders, 238(6):305-310.

Stockdale, L.,Coyne, S. \& Padilla-Walker, L. (2018). Parent and child technoference and socioemotional behavioral outcomes: A nationally representative study of 10- to 20year-old adolescents. Computers in Human Behavior. 88 (8):219-226.

Swenda, M. \& Henry, O. (2016). Common risk factors associated with adolescent and young adult depression. Journal of Health \& Human Services Administration, 39(2): 283310.

Tang, W.,Wang, G.,Hu, T., Dai, Q., Xu, J.,Yang, Y. \& Xu, J.(2018). Mental health and psychosocial problems among Chinese left-behind children: A cross-sectional comparative study. Journal of Affective Disorders. 241(9):133-141.

Tözün, M. \& Ünsal A. (2008). Prevalence of people showing over threshold depressive symptom in 40years and over aged. TAF Preventive Medicine Bulletin, 7(6): 485-490.

Trudeau, L., Spoth, R., Mason, W. A., Randall, G. K, Redmond, C. \& Schainker, L. Effects of adolescent universal substance misuse preventive interventions on young adult depression symptoms: Mediational modelling. Journal Of Abnormal Child Psychology, 44(2): 257-68.

Varma, S. G., Uğurlu, T. T., Korkmaz, A. \& Oğuzhanoğlu, K. N. (2012). Sociodemographic and Clinical Features of Elderly People with a Diagnosis of Depression. New Symposium Journal, 50(2): 90-94.

Wang, F.,Zhang, Q.,Zhang, L. Ng, C., Ungvari, G.,Yuan, Z., Zhang, J. \& Xiang, Y. (2018). Prevalence of major depressive disorder in older adults in China: A systematic review and meta-analysis. Journal of Affective Disorders, 241(8):297-304.

Wolanin, A., Hong, E., Marks, D., Panchoo, K. \& Gross, M. (2016).Prevalence of clinically elevated depressive symptoms in college athletes and differences by gender and sport. British Journal of Sports Medicine. 50(3): 167-171.

Yazgan, Ç., Kora, K., Topçuoğlu, V. \& Kuşçu, K. (2006). Factors influencing quality of life of nondemented elderly nursing homes residents. Turkish Journal of Geriatrics, 9(3): 143-149.

Yuko, M., Taeko, S., Shoichi, A. \& Yuichi, I. (2015). The impact of a delaved sleep wake Schedule on depression is greater in women -a web-based cross-sectional study in Japanese young adult. Chronobiology International: The Journal of Biological \& Medical Rhythm Research. 32(7): 952-958.

Zhao, X.,Zhang, D.,Wu, M.,Yang, Y., Xie, H., Li, Y., Jia, J. \& Su, Y. (2018). Loneliness and depression symptoms among the elderly in nursing homes: A moderated mediation model of resilience and social support. Psychiatry Research. 268(9):143-151. 
